\title{
Concepções de enfermeiras sobre o prolongamento artificial da vida
}

\author{
Nurses' view on artificial extension of life \\ Concepciones de enfermeras sobre la prolongación artificial de la vida
}

\author{
Carina Marinho Picanço'; Dora Sadigursky ${ }^{I I}$
}

\begin{abstract}
RESUMO: Os pacientes fora de possibilidade de cura continuam sendo alvos da obstinação terapêutica nas unidades de terapia intensiva (UTI). Esta pesquisa descritiva teve como objetivo analisar as concepções das enfermeiras sobre o cuidado aos pacientes em prolongamento artificial da vida em UTI. Foi desenvolvido em 2009, na UTI de um hospital público, na cidade de Salvador, Bahia. Foram entrevistadas 17 enfermeiras e os dados tratados conforme a análise de conteúdo temática de Bardin. Como resultado obteve-se a categoria principal: Percebendo a obstinação terapêutica. E as subcategorias: Acreditando no limite da vida; Sofrendo com o prolongamento artificial da vida. Conclui-se que as enfermeiras acreditam que deve existir limitação nas condutas terapêuticas e consideram o prolongamento artificial da vida fonte geradora de sofrimento para o paciente.

Palavras-Chave: Cuidados paliativos; unidades de terapia intensiva; obstinação terapêutica; enfermagem.
\end{abstract}

\begin{abstract}
Patients with no chance of cure in intensive care unit (ICU) are still targets of therapeutic obstinacy. This descriptive study aimed at analyzing views of female nurses on the care of ICU patients by means of artificial prolongation of life. It was carried out in the ICU of a large public hospital in the city of Salvador, Bahia, Brazil, in 2009. Seventeen (17) nurses were interviewed and data were treated on the basis of Bardin's thematic content analysis. The main outstanding category was Acknowledging therapeutic obstinacy; with the outstanding subcategories Acknowledging limits to life; Suffering from artificial prolongation of life. Conclusions show nurses believe there should be limits to therapeutic approaches and they consider artificial prolongation of life to be a source for patient's suffering.

Keywords: Palliative care; intensive care units; therapeutic obstinacy; nursing.
\end{abstract}

RESUMEN: Los pacientes sin posibilidad de cura siguen siendo víctimas de la obstinación terapéutica en las unidades de cuidados intensivos ( $\mathrm{UCI}$ ). Este estudio descriptivo tuvo como objetivo analizar las concepciones de las enfermeras sobre el cuidado a los pacientes en prolongación artificial de la vida en UCI. Fue desarrollado en 2009, en la UCI de un hospital público, en la ciudad de Salvador, Bahia-Brasil. Se entrevistaron 17 enfermeras y los datos procesados de acuerdo con el análisis de contenido temático de Bardin. Como resultado se obtuvo la categoría principal: percibiendo la obstinación terapéutica. Y las subcategorías: Creyendo en el límite de la vida; Sufriendo con la prolongación artificial de la vida. En conclusión, las enfermeras creen que debe haber limitaciones en los enfoques terapéuticos y quea si la prolongación artificial de la vida es una fuente de sufrimiento para el paciente.

Palabras Clave: Cuidados paliativos; unidades de cuidados intensivos; obstinación terapéutica; enfermería.

\section{INTRODUÇÃO}

A sociedade ocidental atual continua temendo a morte, evitando encará-la e aceitá-la como algo natural e inevitável. No entanto, o que parece curioso é o fato dessa realidade não ser diferente entre os profissionais de saúde que, também, tentam fugir da morte, mesmo lidando quase que cotidianamente com ela. Além da formação fundamentada no modelo biomédico, que busca a cura através do conhecimento técnico, como ferramenta suficiente, a equipe tem à disposição todo aparato tecnológico que, cada vez mais, tem invadido o cenário hospitalar.

Nesse contexto, a morte é reafirmada como algo indesejado que deve ser combatido. Assim, as enfermeiras, consoante as transformações na área da saúde, parecem compartilhar dessa luta incessante contra a morte, de forma a perpetuar sua não aceitação. Desse modo, o cuidado de enfermagem parece estar cada vez mais distanciado do seu foco de trabalho, uma vez que este deve ser voltado para o ser humano, na sua integralidade, em todas as fases do ciclo vital, desde o nascimento até a morte.

Com isso, os objetivos do cuidar envolvem aliviar, confortar, ajudar e promover a vida. A cura pode ocorrer ou não, assim como a morte. Porque, para a enfermagem, a finalidade do cuidar é, prioritariamente, aliviar o sofrimento humano, manter a dignidade e propiciar meios para manejar as crises e as experiências do viver e do morrer ${ }^{1}$.

${ }^{I}$ Mestre em Enfermagem pela Universidade Federal da Bahia, Programa de Pós-Graduação em Enfermagem. Enfermeira Intensivista do Hospital Geral Roberto Santos, Unidade de Terapia Intensiva. Docente do Curso Bacharelado em Enfermagem do Centro Universitário Estácio. Salvador, Bahia, Brasil. E-mail: carinamarinho@uol.com.br.

IIProfessor Associado I da Universidade Federal da Bahia, Escola de Enfermagem, Programa de Pós-Graduação em Enfermagem, na linha O cuidar no processo de desenvolvimento humano. Salvador, Bahia, Brasil.E-mail: dora@ufba.br. 
Sendo assim, cuidar não é somente lutar contra a morte, envolve também outros aspectos do processo de morte-morrer. Reconhecer os limites terapêuticos, identificar a irreversibilidade da doença, entre outros meios, mostram outras possibilidades de cuidado para esses pacientes e familiares.

No entanto, mesmo lidando corriqueiramente com pacientes graves na iminência de morte, percebese o despreparo e a resistência dos profissionais de saúde em abordar a temática, além da dificuldade em aceitar a morte como algo natural, sendo esta vista como um fracasso terapêutico. Observam-se pessoas com prognósticos reservados, sem resposta às medidas implementadas e, mesmo assim, sendo submetidas às condutas que não cessam. Assim, as pessoas têm suas vidas prolongadas, mortes arrastadas, permeadas por tratamento ostensivo, doloroso e inútil.

Em contrapartida, tem-se o cuidado paliativo, que consiste na assistência promovida por uma equipe multidisciplinar que objetiva a melhoria da qualidade de vida do paciente e seus familiares, por meio da prevenção e alívio do sofrimento e tratamento da dor².

Nessa perspectiva, este estudo objetivou analisar as concepções das enfermeiras sobre o cuidado aos pacientes em prolongamento artificial da vida em unidade de tratamento intensivo (UTI).

\section{REVISÃO DE LITERATURA}

Desde que surge a vida existem cuidados, porque é preciso tomar conta dela, para que ela possa permanecer. Os seres vivos sempre precisaram de cuidados, porque cuidar é um ato de vida que tem como fim permitir a sua continuidade, ou seja, desenvolver-se e lutar contra a morte 3 .

Dessa forma, pessoas diversas, com diferentes papéis, desenvolveram o cuidado, porém, com objetivos semelhantes. Os que necessitavam de cuidados queriam garantir a sua sobrevivência e evitar a morte. $\mathrm{E}$, aqueles que cuidavam, passaram a lutar contra a morte, de tal forma que propiciaram a perpetuação do tabu que envolve este tema. No entanto, não se deve permitir que essa luta incessante seja o ponto crucial para que o cuidado exista, a morte faz parte da vida e deve ser encarada como natural e irremediável.

O encontro, entre cuidador e o ser cuidado, se dá mediado, de um modo geral, por uma intensa ale-gria (nascimento de um filho) ou por uma tristeza profunda (a morte de um ente querido). Assim, o viver, o adoecer e o morrer implicam alcançar a concretude de valores. Para tanto, o profissional de enfermagem deve estar sensível a esses valores (ético, espiritual) ao cuidar da vida humana. Por isso, o cuidado de enfermagem deve ter, como principal característica, o estímulo às potencialidades das pessoas. Superações antes não pensadas, então, tornam-se concretas, pos- sibilitando que certa beleza da vida humana, mesmo em seu processo de definhamento orgânico, atravesse o sofrimento, o que termina por permitir um bem-estar e um conforto que extrapolam o físico, o biológico e o fisiológico ${ }^{4}$.

Entretanto, transcorridas quase quatro décadas das proposições de mudanças no modelo contemporâneo do morrer, observa-se que, durante seu processo formativo, o profissional de saúde, via de regra, não recebe informação e treinamento suficiente para acompanhar a morte e o processo de morrer. Ao contrário do que se possa pensar, será no hospital que os profissionais serão preparados para o não enfrentamento da morte. Lá serão forjadas as estratégias para controlar as manifestações emocionais dos profissionais, pacientes e familiares ${ }^{5}$.

Com o avanço tecnológico na UTI, foi possível salvar vidas, antes impossível, uma grande contribuição para a medicina. Sendo viável, então, o prolongamento da vida, mas sem a compreensão adequada da faixa terapêutica. Esses esforços, muitas vezes cheios de incertezas, trouxeram para o mundo da medicina e da sociedade o campo da obstinação terapêutica. $O$ fato é que o treinamento desses novos especialistas está focado em tecnologia, e não inclui a reflexão ética sobre o limite terapêutico dos pacientes fora de possibilidade de cura (PFPC) ${ }^{6}$.

Em se tratando de UTI, esta se caracteriza por um cenário de inovação. Assim, o atendimento especializado de enfermagem a pacientes, considerados críticos, potencializa a necessidade de constante desenvolvimento de competências profissionais, entre os que atuam nessa área, que vão além do saber técnico ${ }^{7}$. Nesse cenário, encontra-se o cuidado paliativo, que ajuda a ver o paciente como uma pessoa em sua totalidade, compreendendo a limitação da ciência. Essa mudança na filosofia ainda é bastante desafiadora para a equipe multiprofissional em saúde ${ }^{8}$.

\section{Metodologia}

Trata-se de uma pesquisa descritiva, de natureza quantiqualitativa, realizada em duas UTIs de um hospital público de grande porte na cidade de Salvador-Ba. Este hospital, inaugurado em 1979, é referência para urgências e emergências clínicas, obstétricas e traumáticas, totalizando 546 leitos. Possui o maior complexo de UTI de todo o Estado da Bahia com 144 leitos. O período para coleta compreendeu de janeiro a junho de 2009. As duas UTIs selecionadas foram a UTI adulto (UTI-A) e a UTI pediátrica (UTI-P), nas quais atuavam um total de 48 enfermeiras; destas, apenas 17 foram entrevistadas, por atenderem ao critério de inclusão, ou seja, atuar na assistência por no mínimo dois anos. Foram escolhidas de forma aleatória. Considerou-se o quantitativo de entrevistadas suficiente quando as respostas das entrevistas começaram a se repetir, de 
acordo com a técnica de saturação de dados. Destas 17 enfermeiras que participaram da pesquisa, 10 atuam na UTI-A e sete na UTI-P.

Atendendo ao estabelecido nas Diretrizes do Conselho Nacional de Saúde e na Resolução n ${ }^{\circ}$ 466/2012 sobre pesquisas envolvendo seres humanos ${ }^{9}$, o estudo foi iniciado após aprovação do Comitê de Ética em Pesquisa, correspondendo ao Protocolo $n^{\underline{0}}$ 07/2009 - Folha de Rosto n ${ }^{\circ}$ 245684. Após o fornecimento de informações sobre o projeto, inclusive seu objetivo e a justificativa para o estudo, foi entregue, a cada enfermeira, o Termo de Consentimento Informado Livre e Esclarecido, deixando claro sobre sua livre escolha em participar e/ou desistir em qualquer fase da pesquisa, além de explicitar o instrumento que seria utilizado. Foi atribuída a letra E para cada entrevista, sendo cada uma numerada (Ex: E1, E2, E3, E4) para preservar o anonimato das participantes.

A coleta de dados foi realizada através da técnica de entrevista semiestruturada. O roteiro da entrevista, previamente elaborado, testado e corrigido, constou de questões que caracterizavam o perfil das participantes e questões específicas e subjetivas sobre o tema.

Para o tratamento das variáveis sociodemográficas, utilizou a análise estatística simples (frequência absoluta). Para a abordagem qualitativa, utilizou-se o método de análise de conteúdo temático de Bardin, que propõe um conjunto de técnicas de análise da comunicação verbal aplicado aos discursos, para obtenção de indicadores, qualitativos ou não, que permitam a descrição do conteúdo das mensagens dos entrevistados. Seu método é composto da pré-análise, exploração do material, tratamento dos resultados, inferência e interpretação ${ }^{10}$.

Na pré-análise, foi realizada uma leitura exaustiva das falas das entrevistas e delimitação das unidades de registro, (discursos). Na etapa seguinte, os dados foram classificados, a partir das unidades de registros visando alcançar a compreensão do texto. Na terceira fase, fezse a categorização, classificando os elementos segundo suas semelhanças e por diferenciação, com posterior reagrupamento em função de características comuns.

Assim, a análise dos dados possibilitou agrupar os resultados traçando inicialmente o perfil das participantes da pesquisa de forma descritiva e quantitativa e, posteriormente, por meio da abordagem qualitativa, realizou-se a categorização. Obteve-se a categoria temática 1: Percebendo o processo de morte-morrer, com as subcategorias Dificuldade em aceitar a morte e Aceitando a morte com naturalidade; categoria temática 2: Conflitos no cuidado frente à morte com as subcategorias Cuidado técnico e Cuidado sensível; e a categoria temática 3: Percebendo a obstinação terapêutica com as subcategorias Acreditando no limite da vida e Sofrendo com o prolongamento artificial da vida. Neste artigo, recorte da dissertação de mestrado, é discutida a terceira categoria temática.

\section{Resultados e Discussão}

\section{Perfil das depoentes}

As participantes, todas do sexo feminino, tinham idades compreendidas entre 25 e 45 anos, sendo que 12 pertenciam ao intervalo de 25 a 29 e as demais (5) acima de 30 anos. A maioria (9) declarou professar a religião católica, cinco se consideram espíritas e as demais, uma se diz evangélica, uma convertida em batista e apenas uma admite não ter religião.

O tempo de formação variou de 2 a 22 anos, sendo que o tempo de experiência em UTI oscilou entre 1 ano e 2 meses e 19 anos. A maioria (11) possui Curso de Pós-Graduação em UTI concluído; duas encontram-se cursando a Especialização em UTI; e outras (4) concluíram outras especialidades como Enfermagem do Trabalho (2), Oncologia (1) e Nefrologia (1).

\section{Percebendo a obstinação terapêutica}

Esta categoria abrangeu duas subcategorias que são analisadas a seguir.

\section{Acreditando no limite da vida}

As enfermeiras admitem que a vida tem um limite e que o cuidado implica um encontro que, mesmo ao abranger a ciência biomédica, redimensiona a técnica com vistas à potencialização das capacidades humanas. Não rejeitam o sofrimento e/ou a morte, mas extraem dessas vivências a consciência da condição humana de vulnerabilidade e a capacidade do homem de ir sempre além dos limites das condições objetivas ${ }^{11}$.

Assim, os avanços tecnológicos na área médica e a busca insensata pela imortalidade do ser humano deslocaram o cenário da morte do seio familiar para o ambiente hospitalar, no qual, geralmente, o moribundo é afastado dos seus entes queridos, confinado à dependência de aparelhos e a procedimentos invasivos, rodeado por profissionais que, obstinados pela cura da doença, teimam em prolongar-lhe a espera da morte, mesmo que essa já seja iminente ${ }^{12}$.

Foi do seguinte modo que as entrevistadas demonstraram a aceitação do limite da vida, conforme destacam em seus depoimentos:

Tudo tem seu limite. Todo mundo vem aqui com um tempo determinado de ir embora. (E8)

A partir do diagnóstico você já começa a pensar em morte [...] Nestes casos sem diagnóstico, com prognóstico fechado... A gente vê aquele paciente definhando. (E10)

[...]deixar que ele faça aquele processo de nascer e morrer que é [...] uma coisa natural, então eu acho que quando você chega naquele, no processo final de morte, $[\ldots]$. (E5)

Para aqueles pacientes que a gente vê que realmente não têm muita perspectiva. (E13) 
A partir do diagnóstico, você já começa a pensar em morte. (E6)

A morte coloca o profissional diante de sua própria finitude, gerando conflito interno, dúvidas sobre a eficácia, os objetivos e a relevância de seus cuidados. Em vista disso, o profissional da enfermagem precisa muitas vezes destituir-se daquilo em que acredita para incorporar aquilo que lhe é designado. Oferecer uma morte digna é um desafio, pois envolve o equilíbrio de múltiplas perspectivas e necessidades do paciente, da família e dos próprios profissionais ${ }^{13}$. Reconhecer e aceitar o processo de morte e morrer representam um passo importante para evitar tratamentos ostensivos, a fim de favorecer uma morte digna, conforme as enfermeiras retrataram:

Quando a vida está me dizendo que está chegando a hora [...]Não pode esquecer que a vida tem um fim [...]Determinadas patologias em UTI, você não tem muito para onde avançar [...] Tem que ter um mínimo de bom senso para saber que aquela vida tem um final. [...]. (E11)

E quando a gente percebe [...] que já foi investido tudo que tinha que investir, e que [..] muito provavelmente ele não vai sair daquele [...] quadro, então a gente já começa a trabalhar [...] numa posição de estar mantendo [...] um bom final para ele. [...] uma boa morte [...]. (E17)

A questão da futilidade médica também é um grande desafio. Existem razões pelas quais os médicos devem prestar um bom tratamento de suporte à vida, quando indicado, mas não necessariamente para todos os pacientes. Muitos relutam em suspender o tratamento porque temem consequências legais, embora haja declarações e políticas favoráveis, tanto oriundas do Colégio Americano de Emergências Médicas como da Associação Médica Americana ${ }^{8}$.

Assim, o sucesso do cuidado paliativo, que visa o conforto, a qualidade de vida e a dignidade humana no processo de finitude é proveniente do empenho, da conjunção de saberes e de fazeres da equipe interdisciplinar. Esse modo de cuidar deve ser de responsabilidade de todos os profissionais de saúde, bem como do cliente e cuidadores. Um único profissional não é capaz de atender a todas as necessidades nessas circunstâncias da vida, já que o cuidado é contínuo, e a morte apresentase numa dialógica constante entre certeza e incerteza, podendo acontecer a qualquer momento, conforme pesquisa $^{14}$, corroborado pela depoente seguinte:

Todos os médicos e todos os profissionais de saúde deveriam entender e saber que existe o limite de todo ser humano, de todo corpo humano. (E2)

Para os profissionais de enfermagem são efetivas a superação do biologicismo e a valorização da subjetividade que permeia a existência humana, cuja morte é inevitável, considerando que o homem é um ser para a morte ${ }^{15}$.

\section{Sofrendo com o prolongamento artificial da vida}

O grande leque de possibilidades terapêuticas oferecidas, nos dias atuais, em conjunto com as ambiguidades referentes às tomadas de decisões no fim da vida, geram intensos questionamentos sobre a obstinação terapêutica, pois os múltiplos e modernos tratamentos podem levar ao excesso de investimento, além do fato de não haver consenso sobre o que é o PFPC ${ }^{16}$.

Nessa busca pela cura, prolongam-se os dias daqueles que não apresentarão melhora. Foi consierado, pelas entrevistadas, que esse prolongamento artificial da vida é fonte geradora de sofrimento, seja por parte do paciente, familiar e/ou equipe, conforme evidenciado nas falas que seguem:

Nessa tentativa de prolongar a vida do paciente a gente acaba trazendo mais sofrimento ao paciente [...]Se chegou a vez dele descansar... A gente fica brincando de Deus, prolongando mais ainda. (E9)

Eu acho que a gente prolonga o sofrimento do paciente. Cabe ao paciente, se tiver condições, e ao familiar decidirem até onde vai o limite terapêutico dele [...]. (E6)

A gente tem a obrigação de proporcionar uma boa morte, digna, sem prolongamento de sofrimento. (E2)

Em se tratando de pediatria, para as crianças com mau prognóstico, o desenlace fatal se prolonga, sendo percebido pelas enfermeiras como um desgaste humano, material e familiar desnecessário ${ }^{17}$. Nesse setor, no qual se tem a presença constante dos pais e/ ou responsáveis, percebe-se uma preocupação que se estende a eles, conforme evidenciado a seguir.

Pacientes sem perspectivas de vida eu acho que. [...] prolongar a vida é prolongar o sofrimento, sofrimento dos pais, o sofrimento da criança. (E15)

Alguns aspectos chamam a atenção nas falas anteriores, como limite terapêutico e boa morte, o que remete ao respeito à condição clínica de cada paciente e à adoção de uma assistência não direcionada para a cura, mas sim para os cuidados paliativos que transformem o processo-morte desse doente em algo mais humano e dignificador.

O tratamento fútil, advindo da internação na UTI, proporcionou severa violação à integridade psico-física do paciente terminal, impossibilitando-o de exercer o direito a uma existência digna. Tal fato logrou vitimar o doente terminal, cujos procedimentos médicos invasivos, desvinculados de uma finalidade curativa, proporcionaram-lhe apenas o prolongamento de sua morte e o isolamento daque-les que realmente o amavam ${ }^{11}$. Isto é reforçado nos trechos seguintes:

Eu acho que, muitas vezes, fica prolongando um sofrimento, que não vai levar a lugar nenhum. Antes os pacientes morriam em suas casas, com seus familiares, de uma forma mais natural e, hoje em dia, morrem em UTI, cheios de tubo, de drenos. E, muitas vezes os 
médicos sabem que aquele paciente não vai ter uma vida normal, não vai viver e, mesmo assim, ficam prolongando... Porque a medicina desenvolveu tecnologias que permitem prolongar esse sofrimento. (E3)

Acho que esse prolongamento artificial da vida é uma coisa agressiva, tanto para a equipe quanto para a família. (E7)

Muitas vezes, a estrutura e a dinâmica atual da família não permitem que esse moribundo volte para seu lar para viver seus momentos finais. Os estudos reafirmam que os hospitais devem desenvolver uma abordagem sistemática para garantir que, na admissão e diariamente durante a hospitalização, os pacientes possam ser identificados e acompanhados pela equipe de cuidados paliativos ${ }^{18}$.

São várias as estratégias que se pode utilizar para minimizar o sofrimento, uma delas é o envolvimento do familiar nesse processo de dor e perda. Uma maneira simples é tornar mais acessíveis e flexíveis a entrada e permanência dos familiares junto aos seus entes, o que é reforçado por alguns depoimentos:

Eu sou contra prolongar a vida de um paciente que [...] está na iminência de morte. Eu sou a favor de um cuidado paliativo, aquele para amenizar o sofrimento mesmo. [...] Eu sou a favor dessas unidades que você pode manter o paciente, no momento final, próximo à família e com cuidados básicos. Porque aqui [na UTI] é muito frio. Naquele momento, a família quer ficar o tempo todo, até o último momento, em contato com o corpo físico e a gente acaba privando-a, porque tem um horário predeterminado de visitação. (E5)

[...] ]aqui no hospital [...] as medidas são meio esdrúxulas. (E1)

Nesse sentido, tais medidas, consideradas esdrúxulas pela depoente anterior, caracterizam-se pela obstinação terapêutica, que é uma das formas mais desumanas de negação da morte, por meio da exacerbação do sofrimento e da angústia nos momentos derradeiros do ser humano.

Assim, é interessante que haja uma equipe de cuidados paliativos para que, juntamente com o especialista, possam envolver-se em discussões sobre os cuidados, visando à compreensão realista dos resultados. Essas discussões podem considerar as terapias avançadas, como o uso de inotrópicos, drogas vasodilatadoras ou transplante de coração. Ou, em alternativa, cuidados paliativos para aqueles que estão fora de possibilidade de cura $^{19}$. E, nessa perspectiva, assim se manifestaram as entrevistadas:

Acho que a questão da conversa com a família é muito importante, para que não haja esse sofrimento inútil por parte do paciente. (E4)

Para aqueles pacientes que a gente vê que realmente não têm muita perspectiva e tentar prolongar cada vez mais, é difícil, [...] você investe com drogas e medicações e ele não responde [...]Às vezes o melhor é mandar [...] para o quarto para ficar com a família [...]. (E13)

Dessa maneira, há necessidade de uma política direcionada para os cuidados com foco no conforto e redução da dor do paciente e que as enfermeiras se tornem imprescindíveis, funcionando como o elo de articulação entre os demais profissionais e práticas ${ }^{20}$.

\section{Conclusão}

As enfermeiras entrevistadas entendem que o tratamento adequado, para os pacientes gravemente enfermos, deve ser pautado na resposta individual que eles apresentam às terapêuticas implementadas, conforme foi observado na categoria principal identificada - Percebendo a obstinação terapêutica e subcategorias emergentes - Acreditando no limite da vida e Sofrendo com o prolongamento artificial da vida.

É preciso deixar claro, nesta conclusão, que não se propõe o desligamento dos aparelhos e a suspensão das medidas terapêuticas. Mas, sugere-se uma reflexão sobre o tema, para que seja abordado com mais naturalidade por aqueles que cuidam de PFPC, a fim de que se possa proporcionar uma morte digna, com mais conforto e cuidados necessários. Portanto, é preciso pensar nos cuidados paliativos como alternativa para os pacientes que não respondem mais às medidas implementadas.

Quanto aos limites da pesquisa realizada, destaca-se a necessidade de novos estudos sobre o tema obstinação terapêutica, que analisem as concepções de outros membros da equipe multidisciplinar e de familiares dos pacientes, que entram no processo de morte e morrer nas UTIs.

Faz-se necessário repensar as unidades hospitalares, em especial em sua reestruturação, para acolher esses pacientes através de unidades e/ou equipes de cuidados paliativos, visando ao tratamento mais adequado, mediante o conforto e o alívio da dor do paciente e familiares.

\section{REFERÊNCIAS}

1.Waldow VR. Cuidado humano: o resgate necessário. 2a ed. Porto Alegre (RS): Sagra Luzzatto; 1999.

2.WHO. Palliative care is an essential part of cancer control [site da Internet]. 2002 [citado em 25 ago 2014]. Disponível em: http://www.who.int/cancer/palliative/en/. 3.Colliére MF. Promover a vida. Lisboa (Pt): Sindicato dos Enfermeiros Portugueses; 1989.

4.Gomes AMT. Entre Agostinho de Hipona e Florence Nightingale: o cuidado de enfermagem en-trelaçado com o belo. Rev enferm UERJ. 2013; 21:703-4.

5.Borges MS, Mendes N. Representações de profissionais de saúde sobre a morte e o processo de morrer. Rev Bras Enferm. 2012; 65: 324-31. 
6.Martinez MLC, Velarde MCC. Dilemas bioéticos y sus posibles soluciones en las unidades de te-rapia intensiva pediátrica del Distrito Federal (México). Acta Bioeth. 2013; 19: 275-83.

7.Camelo SHH, Silva VLS, Laus AM, Chaves LDP. Perfil profissional de enfermeiros atuantes em unidades de terapia intensiva de um hospital de ensino. Cienc enferm. 2013; 3: 51-62.

8.Quest TE, Chan GK, Derse A, Stone S, Todd KH, Zalenski R. Palliative care in emergency medi-cine: past, present, and future. J Palliat Med. 2012; 15: 1076-81.

9.Ministério da Saúde (Br). Conselho Nacional de Saúde. Resolução $n^{\circ}$ 466: relativo a pesquisa envolvendo seres humanos. Brasília (DF): CNS; 2012.

10.Bardin L. Análise de conteúdo. Tradução de Luis Antero e Augusto Pinheiro. São Paulo: Edições 70; 2011. 11.Gomes AM, Espirito Santos CC. A espiritualidade e o cuidado de enfermagem: desafios e pers-pectivas no contexto do processo saúde-doença. Rev enferm UERJ. 2013; $1: 261-4$.

12.Marreiro, CL. Responsabilidade civil do médico na prática da distanásia. Rev bioét. 2013; 21: 308-17.

13.Souza LF, Misko MD, Silva L, Poles K, Santos MR, Bousso RS. Morte digna da criança: per-cepção de enfermeiros de uma unidade de oncologia. Rev esc enferm USP. 2013; 47: 30-7.
14.Silva MM, Moreira MC, Leite JL, Erdmann AL. $O$ trabalho noturno da enfermagem no cuidado paliativo oncológico. Rev Latino-Am Enfermagem. 2013; [citado em 10 abr 2014] 21(3): [7 telas]. Disponível em: http://www.scielo.br/pdf/rlae/v21n3/pt_0104-1169. rlae-21-03-0773.pdf

15.Silva Júnior FJG, Santos LCS, Moura PVS, Melo BMS, Monteiro CFS. Processo de morte e morrer: evidências da literatura científica de enfermagem. Rev Bras Enferm. 2011; 64: 1122-6.

16.Silva KCO, Quintana AM, Nietsche EA. Perspectiva de médicos e enfermeiros. Esc Anna Nery. 2012; 16: 697-703. 17.Garcia V, Riveros ER. Experiencia de enfermeras intensivistas pediátricas en la muerte de un niño: vivencias, duelo, aspectos bioéticos. Cienc enferm. 2013; 2: 111-24. 18 .Weissman DE, Meier DE. Identifying patients in need of a palliative care assessment in the hos-pital setting a consensus report from the center to advance palliative care. J Palliat Med. 2011; 14(1): 1-7.

19.Gelfman LP, Kalman J, Goldstein NE. Engaging heart failure clinicians to increase palliative care referrals: overcoming barriers, improving techniques. J Palliat Med. 2014; 17: 753-60.

20.Silva KS, Kruse MHL. Em defesa da sociedade: a invenção dos cuidados paliativos e a produção de subjetividades. Rev esc enferm USP. 2012; 46: 460-5. 